UDC 616.12-008.46:615.361:611-018.5.013.8

\title{
CHANGES OF INTRACARDIAC HEMODYNAMICS IN PATIENTS WITH DECREASED MYOCARDIAL CONTRACTILITY AT TRANSPLANTATION OF CORD BLOOD STEM CELLS
}

\section{ABSTRACT}

Experiments on animals have shown an effectiveness of cord blood stem cells (SCs) in restoration of myocardial contractility. But there is not enough information about the use of this SCs type at heart lesion in people.

Therefore, the aim of this study was to analyze the effect of cord blood SCs transplantation on impaired myocardial contractility of patients with chronic heart failure.

MATERIALS AND METHODS. According to the data echocardiography we analyzed the changes of intracardiac hemodynamics in patients with decreased myocardial contractility, who underwent intravenous transplantation of cord blood stem cells in case of ineffective traditional conservative therapy schemes of heart failure (HF).

RESULTS. Left ventricular ejection fraction before cord blood stem cells transplantation was $22.0 \pm 5.0 \%, 1$ month after SCs transplantation $22.3 \pm 6.5 \%$, and in 3 months $-28.5 \pm 7.8 \%(p<0.05)$. The average stroke index increased from $21.3 \pm 3.5 \mathrm{ml} / \mathrm{m}^{2}$ before transplantation up to $29.0 \pm 8.5 \mathrm{ml} / \mathrm{m}^{2} 3$ months after SCs transplantation $(p<0.05)$. Statistically significant changes of diastolic function parameters (index $e^{\prime}, E / A$, $\left.E / e^{\prime}\right)$ and venous stasis have not been established. Before transplantation local cell contractility index (LCl) of basal and middle segments was 2.43 points; 1 month after transplantation $\mathrm{LCl}$ decreased to 2.38, and after 3 months - up to 2.18 points $(p<0.05)$.

CONCLUSION. In a short term (1-3 months) after transplantation of cord blood cells there was demonstrated a partial restoration of parameters that characterize left ventricular systolic function, and a significant improvement of impaired heart rate mechanics. No negative effects, complications and side effects have been recorded in short periods of observation after transplantation of cord blood cells.

KEYWORDS : chronic heart failure; left ventricular ejection fraction; cord blood stem cells; cell therapy

Until now, ischemic heart disease and chronic heart failure (HF) remain the biggest problem of health care in the world [1]. Due to diseases of cardiovascular system and reduction of heart pumping function millions of people live with HF [2]. There were developed many methods of HF treatment, but in some cases they do not solve the problem. One of the newest and prospective approaches is stem cells (SCs) transplantation. In most researches SCs transplantation led to significant improvement of contractile ability of the left ventricle (LV) myocardium in both animals
[3] and people $[4,5]$ at ischemia lesion. It was proved that stem cells improve patients' survival and quality of life [6]. However, several other studies have shown a chance of complications and adverse side effects at SCs transplantation [7-9]. These differences are explained by the use of SCs from various sources and, consequently, with different properties.

Experiments on animals have shown an effectiveness of cord blood SCs in restoration of myocardial contractility [10-13]. But there is not enough information about the use of this SCs type at myocardial lesion 
in human. Therefore, the aim of this study was to analyze the effect of cord blood SCs transplantation on impaired myocardial contractility of human heart.

\section{MATERIAL AND METHODS}

The research was based on the analysis of the period after transplantation in short terms in 6 patients with HF stage IIa-IIb, III-IV functional class by NYHA and low (less than 35\%) ejection fraction (EF) of LV. The traditional scheme of conservative HF treatment (beta blockers, ACE inhibitors and diuretics) in this group of patients was not effective. General characteristics of the group are summarized in Table. 1. Evaluation of cell therapy efficiency in patients with impaired myocardial contractility was performed at baseline; before cell transplantation and at the end of the $1^{\text {st }}$ and $3^{\text {rd }}$ months after transplantation.

SCs transplantation in patients was performed by their informed consent in accordance with the clinical trial program of cell drug "Cryopreserved human umbilical cord blood". The cell preparation include of immature committed hematopoietic progenitors and mature blood cells. The number of nucleated cells in the samples ranged from $0.89 \cdot 10^{9}$ to $0.95 \cdot 10^{9}$, the number of mononuclear cells - from $0.486 \cdot 10^{9}$ to $0.520 \cdot 10^{9}, \mathrm{CD}^{2} 4^{+}$cells - at least $1.00 \pm 0.01 \cdot 10^{3}$. Cell suspension, diluted in $200 \mathrm{ml}$ of saline, was injected intravenously at a rate of 2-3 $\mathrm{ml} / \mathrm{min}$.

EchoCG of patients was performed using ultrasound scanner Aplio 500 (Toshiba, Japan). For the assessment of intracardiac hemodynamics and indicators of systolic and diastolic function of the heart muscle we used generally accepted methods [14]. To detect local contractile disorders, LV was conventionally divided into segments, located in the plane of the three cross-sections of the heart. In semi-quantitative assessment of local contractility disorders we calculated local contractility index ( $\mathrm{LCl}$ ), which was the sum of each segment contractility scoring (S), divided by the total number of studied LV segments $(n)$ : ILS $=\Sigma S / n$, where normokinesis corresponded to 1 point, moderate hypokinesis 2 points, expressed hypokinesis -3 points, akinesis -4 points. At the research stages the statistical significance of the differences between the registered parameters was determined using $U$ Mann-Whitney criteria. Differences were considered credible at $p<0.05$.

\section{RESULTS AND DISCUSSION}

The output state of intracardiac hemodynamics in all studied patients was characterized by reduction of both systolic and diastolic function. Results of patients' examination are generalized in Table 1. Thus, there was registered a significant reduction in LV EF and stroke index (SI). Reduction of LV EF is caused by a significant decrease of end-systolic index (ESI) with a relatively normal value of end-diastolic index (EDI). Hyperkinesis or aneurysms were not registered in the studied basal and middle segments of sections. We detected significant contractility abnormality in $71 \%$ of them. $\mathrm{LCl}$ of basal and middle segments was 2.4 points.

Reduction of diastolic heart function in patients with heart failure was manifested by reduction of indicator of early diastolic speed of mitral annulus movement ( $\mathrm{e}^{\prime}$ ) in the patients up to $7.2 \pm 0.42 \mathrm{~cm} / \mathrm{s}$ (from 6.9 to 7.8). That testified to the slowing of LV relaxation. Ratio of peak velocities of early and late diastolic filling of LV $(E / A)$ was within the normal range $(1.58 \pm 0.33$; range 1.2-2.0), which we treated as a pseudo normalization and diastolic dysfunction type II. The ratio value of early diastolic filling velocity of LV to the index of early diastolic velocity of the annulus (figure E/e') was in the range of intermediate values (10.4 \pm 2.1 (from 8.9 to 13.4) and did not give unambiguous interpretation.

There was a venous congestion in a systemic circulation, with increase of pressure in the right atrium and changing conditions of blood flow through the heart valves. Thus, before SCs transplantation mean right atrial pressure was $10.3 \pm 3.4 \mathrm{~mm}$ (from7 to 16). The average diameter of the inferior vena cava was $17.0 \pm 2.6 \mathrm{~mm}$. (from 15.2 to 20), and its average collapse at inhale $-64.0 \pm 5.3 \%$ (60 to 70 ). Before SCs transplantation pulmonary hypertension was registered in $50 \%$ of patients, but it was not manifested clinically. Thus, the average systolic pressure in the pulmonary artery (PA) was $35.0 \pm 12.1 \mathrm{~mm}$ (from 22 to 52 ). These hemodynamics changes in the right heart could be explained by the decrease of pump function of LV, which led to blood stagnation in pulmonary circulation and, as a consequence, to volume overload of the right ventricle and development of right heart failure.

In addition, before SCs transplantation all patients had dysfunction of the heart valves. Thus, in $16.6 \%$ of patients there was expressed regurgitation on mitral valve, in $33.3 \%$ - moderate, in the other $50 \%$ minimal or slight. Regurgitation on the tricuspid valve in $16.6 \%$ of patients was expressed and in other $16.6 \%$ - moderate. Regurgitation in aortic valve was minimal and clinically insignificant. Geometric parameters of the heart chambers were about the age norm of patients.

In a short time after SCs transplantation there was registered positive dynamics of the major indicators of intracardiac hemodynamics and parameters of myocardial reduction compared to the initial state (Table. 3). In a month the changes of the parameters were not significant, but in 3 months after SCs transplantation EF growth was 27\%, and SI growth was $36 \%$ from the initial state. It could indicate an improvement of LV function. In the analysis of changes in segmental contraction we registered the reduce of segments with significant myocardial disorders (see Table. 2): 1 month after SCs transplantation LCI decreased to 2.4, and after 3 months - up to 2.2 points. Thus, SCs transplantation in the complex of conservative treatment of chronic HF of ischemic

Table 1. Patients' characteristics.

\begin{tabular}{|c|c|c|c|c|}
\hline \multicolumn{1}{|c|}{ № } & $\begin{array}{c}\text { AGE } \\
\text { (YEARS) }\end{array}$ & SEX & $\begin{array}{c}\text { CLASS OF HF } \\
\text { BY NYHA }\end{array}$ & $\begin{array}{c}\text { HF } \\
\text { STAGE }\end{array}$ \\
\hline Patient 1 & 47 & Male & III & II a \\
\hline Patient 2 & 14 & Male & III & II b \\
\hline Patient 3 & 54 & Male & III & II b \\
\hline Patient 4 & 57 & Male & IV & II a \\
\hline Patient 5 & 49 & Male & IV & II b \\
\hline Patient 6 & 52 & Male & III & II b \\
\hline
\end{tabular}

Table 2. Intracardiac hemodynamics and disorders of local contractility in patients with myocardial ischemic lesions before SC transplantation $(n=6)$

\section{INDEX}

Ejection fraction of left ventricular

Average stroke index

End-systolic index

End-diastolic index

The average number

of segments with normokinesis

in the basal and middle sections

The average number

of segments with hypokinesis

in the basal and middle sections

The average number

of segments with akinesis

in the basal and middle sections
RATE

$22.0 \pm 5.0 \%$ (from 17 till 28$)$

$21.3 \pm 3.5 \mathrm{ml} / \mathrm{m}^{2}$ (from 16 till 23 )

$78.3 \pm 15.8 \mathrm{ml} / \mathrm{m}^{2}$ (from 61 till 98)

$99.8 \pm 16.0 \mathrm{ml} / \mathrm{m}^{2}$ (from 84 till 122)

$3.5(29 \%)$

$5.3(45 \%)$

$3.2(26 \%)$
Note: * $-\%$ of segments with normokinesis, hypokinesis and akinesis was calculated from the total number of segments studied in the basal and middle sections of the heart $(n=12)$. 
genesis allowed significant improving of intracardiac hemodynamics and myocardial contractility performance throughout the short-term (1-3 month) period.

A month after SCs transplantation echocardiographic pattern of diastolic dysfunction remained. Indicator E/A did not change significantly over a short observation period: in 1 month $-1.60 \pm 0.14$, and in 3 months $-1.73 \pm 0.17$. However, there was an increase of indicator $e^{\prime}$ to normal values by the end of the $1^{\text {st }}$ month of observation $11.0 \pm 3.3$ $\mathrm{cm} / \mathrm{s}$ (from 7.2 to 12.9 ), and by the end of the $3^{\text {rd }}$ month $-10.9 \pm 3.7$ (from 8.4 to 15.2). Index E/e' to the end of the $1^{\text {st }}$ month of observation corresponded to normal values $-6.2 \pm 1.8$ (from 4.4 to 8 ), but at the end of the $3^{\text {rd }}$ month this indicator was ambiguous $-9.4 \pm 3.2$ (from 6.6 to 12.8). Thus, despite minor fluctuations in diastolic dysfunction at the end of the 1st month of observation, there was recorded a tendency to improvement of heart diastolic function.

Venous congestion in the system of the inferior vena cava was significantly expressed. Thus, average diameter of the inferior vena cava was $20.3 \pm 2.8 \mathrm{~mm}$ (from 15.6 to 23.7), while the average collapse during inhalation was $51.7 \pm 12.2 \%$ (from 40 to 72 ). Average pressure in the right atrium was $10.8 \pm 2.9 \mathrm{~mm}$ (from 7 to 15 ). Therefore, hemodynamics of the right atrium and the inferior vena cava system has not changed during the first month after SC transplantation. By the end of the $3^{\text {rd }}$ month of observation we registered the following changes of EchoCG indices of heart diastolic function: an average pressure in the right atrium was $10.2 \pm 3.6 \mathrm{~mm}$ (from 6 to 15); an average diameter of the inferior vena cava was $18.5 \pm 3.1 \mathrm{~mm}$ (from 14 to 22 ), with an average collapse during inhalation $-41.2 \pm 14.8 \%$ (from 21 to 60 ).

Registered change of inferior vena cava collapse during inhalation (up to the 3rd month of observation average collapse decreased by $23 \%$ ).
It can be explained by a decrease of blood volume as a result of diuretic therapy.

In a month after SCs transplantation pulmonary hypertension was observed in $50 \%$ of patients, and an average pressure in the pulmonary artery was $34.8 \pm 12.4 \mathrm{~mm}$ (from 20 to 54 ), which hardly differed from similar indicators before SCs transplantation. In 3 months after SCs transplantation asymptomatic pulmonary hypertension was observed in $33.3 \%$ of patients with an average value of pulmonary artery pressure $29.2 \pm 10.6 \mathrm{~mm}$ (from 15 to 45 ). During the observations we registered reducing of pulmonary hypertension to $16.6 \%$, compared to the initial state. Significant reduction of average systolic pulmonary artery pressure was in 2-3 months of research, which could be explained by descending stagnant phenomena with improvement of LV systolic function.

Any significant changes in the degree of mitral valve regurgitation and tricuspid valve regurgitation in the entire observation period in most patients were not recorded. Some improvements of atrioventricular valve function in 3 months after SCs transplantation are likely due to partial restoration of ventricular geometry and improvement of segmental myocardial contractility.

Thus, intracardiac hemodynamics in patients with chronic HF of ischemic genesis before SCs transplantation was characterized by severe systolic and diastolic dysfunction in LV. Throughout the short-term (1 and 3 months) follow-up period some disorders of systolic cardiac function were recorded. After SCs transplantation we observed a significant positive dynamics of changes in echocardiographic parameters reflecting systolic function of the heart. Echocardiographic parameters that characterize the diastolic dysfunction had insignificant improvement in respect of baseline in 3-month observation period.

Table 3. Intracardiac hemodynamics and disorders of local contractility before and in short periods of observation after SCs transplantation $(n=6)$.

\begin{tabular}{|c|c|c|c|c|}
\hline \multirow[b]{2}{*}{ INDEX } & \multicolumn{2}{|l|}{$1^{\text {sT }}$ MONTH } & \multicolumn{2}{|l|}{$3^{\text {RD }}$ MONTH } \\
\hline & & $\begin{array}{l}\text { \% FROM } \\
\text { INITIAL } \\
\text { STATE }\end{array}$ & & $\begin{array}{l}\text { \% FROM } \\
\text { INITIAL } \\
\text { STATE }\end{array}$ \\
\hline Ejection fraction of left ventricular & $22.3 \pm 6.5 \%$ (from 16 to 29 ) & +1.4 & $28.5 \pm 7.8 \%$ (from 23 to 34 ) & $+27.3^{*}$ \\
\hline Stroke index & $20.7 \pm 8.4 \mathrm{ml} / \mathrm{m} 2$ (from 11 to 26 ) & -2.8 & $29.0 \pm 8.5 \mathrm{ml} / \mathrm{m} 2$ (from 23 to 35 ) & $+36.2^{*}$ \\
\hline End-systolic index & $70.3 \pm 13.7 \mathrm{ml} / \mathrm{m} 2$ (from 61 to 86 ) & -10.2 & $73.5 \pm 6.4 \mathrm{ml} / \mathrm{m} 2$ (from 69 to 78 ) & $-6.1^{\star}$ \\
\hline End-diastolic index & $91.0 \pm 19.5 \mathrm{ml} / \mathrm{m} 2$ (from 72 to 111$)$ & -8.8 & $102.5 \pm 2.1 \mathrm{ml} / \mathrm{m} 2$ (from 101 to 104 ) & $+2.7^{*}$ \\
\hline $\begin{array}{l}\text { The average number of segments } \\
\text { with normokinesis in the basal } \\
\text { and middle sections }\end{array}$ & $4.0(33 \%)$ & $+14.3^{\star}$ & $5.2(43 \%)$ & $+47.6^{*}$ \\
\hline $\begin{array}{l}\text { The average number of segments } \\
\text { with hypokinesis in the basal } \\
\text { and middle sections }\end{array}$ & $5.2(43 \%)$ & -3.14 & $4.3(36 \%)$ & -18.8 \\
\hline $\begin{array}{l}\text { The average number of segments } \\
\text { with akinesis in the basal and } \\
\text { middle sections }\end{array}$ & $2.8(24 \%)$ & $-10.5^{\star}$ & $2.5(12 \%)$ & $-21.1^{*}$ \\
\hline
\end{tabular}

Note: ${ }^{*}-p<0,05$ compared with the initial state.

\section{CONCLUSIONS}

Analysis of the EchoCG changes demonstrated that transplantation of cord blood stem cells in patients with chronic heart failure leads to the recovery of the affected myocardium, resulting in progressive improvement of myocardial contractility in early term after transplantation (1-3 months).

Thus, the SCs transplantation can be an effective procedure in the complex with conservative treatment of cardiovascular system diseases, accompanied by systolic heart failure.

No negative effects, complications and side effects have been recorded in short periods of observation after transplantation of cord blood cells. These preliminary positive results of cord blood SCs transplantation in patients with ischemic myocardial injury give reasons to continue the study. 


\section{REFERENCES}

1. Roger VL, Go AS, Lloyd-Jones DM, et al. Heart disease and stroke statistics-2011 update: a report from the American Heart Association. Circulation. 2011; 123:e18e209.

2. Marelli AJ, Mackie AS, lonescu-lttu R, et al. Congenital heart disease in the general population: changing prevalence and age distribution. Circulation. 2007; 115(2):163-172.

3. Leor J, Guetta E, Feinberg MS, et al. Human umbilical cord blood-derived CD133+ cells enhance function and repair of the infarcted myocardium. Stem Cells. 2006; 24:772-780.

4. Perin EC, Dohmann HF, Borojevic $R$, et al. Improved exercise capacity and ischemia 6 and 12 months after transendocardial injection of autologous bone marrow mononuclear cells for ischemic cardiomyopathy.Circulation. 2004; 110:II-213-II-218.

5. Wollert KC, Meyer GP, Lotz J, et al. Intracoronary autologous bone-marrow cell transfer after myocardial infarction: the B00ST randomised controlled clinical trial. Lancet. 2004; 364:141-148.

6. Strauer B, Yousef M, Schannwell C. The acute and long-term effects of intracoronary stem cell transplantation in 191 patients with chronic heart failure: the STAR-heart study. Eur. J. Heart Fail. 2010; 12:721-729.

7. Sucak GT, Ozkurt ZN, Aki Z, et al. Cardiac systolic function in patients receiving hematopoetic stem cell transplantation: risk factors for posttransplantation cardiac toxicity. Transplant Proc. 2008; 40:1586-1590.

8. Qazilbash MH, Amjad Al, Qureshi S, et al. Outcome of allogeneic hematopoietic stem cell transplantation in patients with low left ventricular ejection fraction. Biol. Blood Marrow Transplant. 2009; 15:1265-1270.

9. Peres $E$, Levine JE, Khaled YA, et al. Cardiac complications in patients undergoing a reduced-intensity conditioning hematopoietic stem cell transplantation. Bone Marrow Transplant. 2010; 45:149-152.

10. Henning RJ, Burgos JD, Ondrovic L, et al. Human umbilical cord stem cells are attracted to myocardial infarctions. Cell Transplant. 2006; 15:647-658.

11. Henning RJ, Burgos JD, Vasko $M$, et al. Human umbilical cord stem cells and myocardial infarction: effect of dose and route of administration on infarct size. Cell Transplant. 2007; 16:907-917.

12. Henning RJ, Shariff M, Ujwala E, et al. Human cord blood mononuclear cells decrease cytokines and inflammatory cells in acute infarcts. Stem Cells Dev. 2008; 17:1207-1220.

13. Henning RJ, Aufman J, Shariff M, et al. Human umbilical cord stem cells decrease fibrosis and increase cardiac function in cardiomyopathy. Reg. Med. $2010 ;$ 5:45-54.

14. Shiller N, Osipov MA. Klinicheskaja jehokardiografija [Clinical echocardiography]. Moskva, Vidar - Moskow, Vidar, $2005 ; 344$ p.

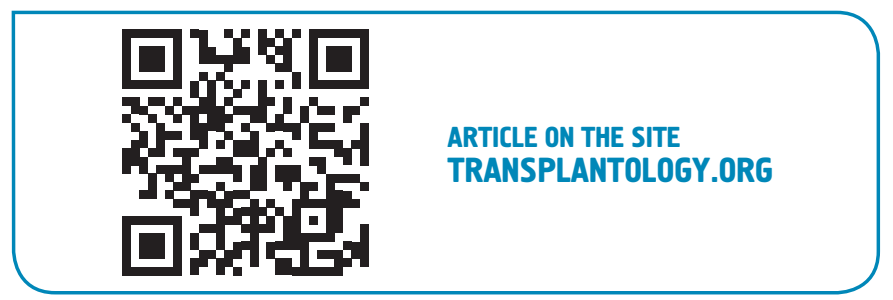

The authors indicate no potential conflicts of interest.

Received: September 19, 2014

Accepted: April 14, 2015 